\title{
What Happened on Deliberation Day?
}

\author{
David Schkade $\dagger$ \\ Cass R. Sunstein $\dagger \dagger$ \\ Reid Hastie $\nmid \dagger \dagger$
}

What are the effects of deliberation about legal and political issues by like-minded people? This Essay reports the results of an experimental investigation involving sixty-three citizens in Colorado. Groups from Boulder, a predominantly liberal city, met to discuss global warming, affirmative action, and civil unions for same-sex couples. Groups from Colorado Springs, a predominately conservative city, discussed the same issues. The major effect of deliberation was to make group members more extreme in their views than they were before they started to talk. Liberals became more liberal on all three issues; conservatives became more conservative. As a result of intragroup deliberation, the division between the citizens of Boulder and the citizens of Colorado Springs significantly increased. Deliberation also increased consensus and significantly reduced diversity within the groups. Even anonymous statements of personal opinion became more extreme and less diverse after deliberation. Because political views are often distributed along geographical lines, these findings are highly likely to be replicated in actual deliberative processes unless safeguards and careful procedures are introduced.

\section{INTRODUCTION}

The American constitutional system aspires to be a deliberative democracy-one that eombines accountability with a high degree of

Copyright (C) 2007 California Law Review, Inc. California Law Review, Inc. (CLR) is a California nonprofit corporation. CLR and the authors are solely responsible for the content of their publications.

$\dagger \quad$ Jerome Katzin Professor, Rady School of Management, University of California, San Diego.

†† Karl N. Llewellyn Distinguished Service Professor, Law School and Department of Political Science, Umversity of Chicago.

$t^{\dagger} \dagger$ Robert S. Hamada Professor of Behavioral Science, Graduate School of Business, University of Chicago. Thanks to Bruce Aekerman for valuable discussions and to Matthew Tokson for excellent research assistance. 
reflection. ${ }^{1}$ Embracing this deliberative ideal, many people have explored the foundations of political deliberation and its implications for legal and political reform. $^{2}$ An evident bope is that deliberation will lead people to accurate understandings and sensible solutions to social problems. Emphasizing that hope, Bruce Ackerman and James Fishkin have argued on behalf of a formal "Deliberation Day," designed to foment citizen deliberation. ${ }^{3}$ But under what circumstances is this hope realistic? What are the likely effects of deliberation on judgments about law and politics?

It should be clear that in order for deliberation to realize its promise, a reasonable variety of views must be expressed and discussed. Without exposure to competing views, citizens cannot engage in a balanced and informed weighing of positions-a prerequisite of effective deliberation. But sufficient diversity is unlikely if people sort themselves into homogeneous groups, or if citizens are segregated geographically; sheer demographics may well mean that many social groups consist of like-minded people. ${ }^{4}$ In fact, there is evidence that different communities in the United States are becoming more homogeneous in ideological terms. ${ }^{5}$ To the extent that this is so, deliberating groups may lack the requisite diversity. What are the effects of deIiberation in these ideologically sorted groups? Perhaps they spread falsehoods rather than truth, or produce confusion rather than clarity.

We created an experiment in political deliberation, designed to examine the effects of deliberation on communities of people having relatively homogenous views - a special kind of Deliberation Day. In this experiment, citizens from two cities in Colorado were assembled into several groups, each containing about six people from a particular city. The groups were asked to deliberate about three highly-contested issues: global warming, affirmative action, and same-sex civil unions. The two cities were Boulder, which is known by its voting patterns to be a predominantly liberal city, and Colorado Springs, known by its voting patterns to be a mainly conservative enclave. ${ }^{6}$ Citizens were first asked to record their views individually and anonymously. After this initial survey, the citizens deliberated about the three issues together and were

1. See Joseph M. Bessette, The Mild Voice of Reason (1994).

2. See Jürgen HaBermas, BetweEN FACTS AND NormS (1996) (elaborating deliberative conception of democracy); DELIBERATIVE DEMOCRACY (Jon Elster ed., 1998) (collecting diverse treatments of deliberative democracy); AMY GuTMANN \& DENNIS ThOMPSON, DEMOCRACY AND DISAGREEMENT (1996) (defending deliberative democracy and discussing its preconditions).

3. See Bruce ackerman \& James S. Fishkin, Deliberation Day (2004).

4. See Diana C. Mutz, Hearing the Other Side 46-48 (2006).

5. See id, see also Bill Bishop, The Great Divide, Austin Am.-Statesman (2004), http://www.statesman.com/greatdivide (showing increased uniformity within communities, defined in geographical terms).

6. David Leip, Atlas of U.S. Presidential Elections, 2004 Presidential General Election Data Graphs Colorado, http://www.uselectionatlas.org/RESULTS/ datagraph.php?year $=2004 \&$ fips $=8 \& f=0 \&$ off $=0 \&$ elect $=0$ (last visited Mar. 5, 2007). 
instructed to reach a group consensus on each issue. After deliberation, individual participants were asked to record their post-deliberation views, again individually and anonymously.

The effects of deliberation on participants were simple. First, the groups from Boulder became more liberal on all three issues; the groups from Colorado Springs became more conservative. Deliberation with like-minded groups thus shifted individual opinions toward more extremity. Second, deliberation increased consensus and decreased diversity. Many of the groups showed substantial heterogeneity in individual opinions before deliberation began. As a result of a brief discussion period, group members showed significantly more agreement and less heterogeneity, not only in their public statements but also in their anonymous post-deliberation expressions of their private views. Third, deliberation sharply increased the disparities between the views of the largely liberal citizens of Boulder and those of the largely conservative citizens of Colorado Springs. Before deliberation, there was considerable overlap between many individuals in the two cities. After deliberation, the overlap in views was much smaller.

The simplest statement of our findings is that deliberation among likeminded people produced ideological amplification-an amplification of preexisting ideological tendencies, in which group discussion leads to greater extremisın. If our experimental findings translate to the real world, deliberation will amplify the ideological tendencies of like-minded people, decrease internal group diversity, and create greater divisions across ideological lines. These effects should be expected whenever groups sort themselves along political lines in purely geographical terms; they should also occur when the sorting occurs through a person's voluntary decisions about what to read in the newspaper and watch on television. ${ }^{7}$

Various kinds of ideological amplification have been established in other experimental settings, but the phenomenon has received little attention in the context of contested political issues. As we shall see, our experimental design diverges from related experiments, including those undertaken by prominent supporters of political deliberation. ${ }^{8}$ In key ways, our design corresponds more closely to the real world of such deliberation, both formal and informal. Our findings therefore have implications for many questions in law and politics. These include the likely judgments of three-judge panels consisting of allRepublican appointees or all-Democratic appointees; the effects of freedom of association; the performance of private or public boards of like-minded people; and the consequences of movements-geographical, technological, or

7. See Shanto Iyengar \& Richard Morin, Red Media, Blue Media, WASH. Post, May 3, 2006, available at http://www.washingtonpost.com/wp-dyn/content/article/2006/05/03/ AR2006050300865.html.

8. See infra notes 79-89 and accompanying text (discussing the treatment of James Fishkin's studies). 
otherwise-that increase the likelihood that like-minded people will form communities of their own.

In this Essay, we report the results of our experiment, offer an explanation for our results, and provide some brief remarks on the implications of those results for deliberation in politics. We suggest that the Colorado experiment has analogies in many domains of democratic life. To be sure, we did not create the kind of Deliberation Day favored by the most enthusiastic proponents of deliberation in public life: we did not offer the various safeguards that they propose, ${ }^{9}$ and indeed our findings might well be taken to provide strong support for those safeguards. But actual deliberation days, and weeks, will often closely resemble our own experiment. As we shall show, our findings offer a vivid warning about the consequences of sorting along political linesand suggest the need for careful design of any proposal intended to promote political and legal deliberation.

\section{I}

\section{Political Deliberation in Colorado}

\section{A. Study Procedures}

Sixty-three voting-eligible adults between the ages of twenty and seventyfive participated; thirty-four participants were women and twenty-nine were men. ${ }^{10}$ Participants were recruitcd from two Colorado counties for a study on opinions about social and political issues by a professional survey research firm using random telephone digit dialing. Each participant received $\$ 100$ for a twohour session. The choice of Colorado as the study's location was purely for logistical convenience of conducting the study; a similar recruitment protocol could have been followed in any state or geographical area.

The study drew half of its sample from Boulder County, which voted $67 \%$ for Democratic candidate John Kerry in the 2004 presidential election. The other half of study participants hailed from the city of Colorado Springs in El Paso County, which voted $67 \%$ for Republican candidate George W. Bush in the same election. ${ }^{11}$ The first and key level of screening for this study was geographical. The study also screened the candidates individually, so as to

9. See ACKERMAN \& FishKin, supra note 3.

10. Consistent with the general demographics of the two counties, $90 \%$ of respondents were white. In both counties, three of the five groups contained one non-white voter. There were no significant differences between groups with and without a white voter on any group or individual responses related to the affirmative action question.

There was no significant difference in age between the samples (the median age was forty-six in both counties). Age did not have a significant effect on the willingness to change one's opinionthe correlation between age and the extent to which a person changed his or her opinion in the direction of the group was +.12 , which is not statistically significant in this sample.

11. CNN.com, 2004 Election Results, http://www.cnn.com/ELECTION/2004/ pages/results/president (last visited Mar. 5, 2007). 
ensure that the Boulder participants held generally liberal political views and the Colorado Springs participants had generally conservative political beliefs. ${ }^{12}$ Despite these general inelinations, we did not screen partieipants for their views on the particular issues involved in the experiment, and many groups showed a degree of pre-deliberation diversity on the issues that they were asked to discuss. There were a total of five conservative groups and five liberal groups, with five to seven members each.

In each county, participants came to a central location at a local university for the study. In the first session, each person completed an individual questionnaire about his or her private personal views on several topics. Participants engaged in this task before being informed that they would be part of a group discussion.

After all participants had completed their individual questionnaires, they were moved to a different room and told that they would discuss some of the issues as a group. The following instructions were read aloud (verbatim) by a study administrator:

Next you will meet as a group to discuss some of the topics you just considered in the survey. As a group, your job will be to try to reach a consensus among you about each topic. As an individual, your job is to express your personal opinion on each discussion topic, and to attempt to reach a group consensus through discussion. You will have I5 minutes per topic.

One member of your group has been randomly selected to be the 'monitor.' The monitor's job is to (1) read instructions and questions aloud to the group, (2) make sure the group performs each discussion task in the proper order, (3) set the timer at 15 minutes for each discussion and (4) record the group's final consensus opinion at the end of each discussion.

The monitor will be given 5 numbered envelopes, which should be opened in numerical order. ${ }^{13}$ For instanee, the monitor will first open

12. Screening questions included the following: (a) "In general, would you describe your political views as very conservative, conservative, moderate, liberal, or very liberal?" (b) "Suppose you were in the voting booth and you came across an office for which two candidates . . . were running and you had never heard of either one. Which candidate would you choose-the Democrat or the Republican-or would you just not vote for that office?" Participants were also asked to assign grades to various people, predicting how they would be as president. The conservative names included Dick Cheney, Wayne Allard (the Republican U.S. Senator from Colorado), Rush Limbaugh, and Pat Robertson. The liberal names included Edward Kennedy, Hillary Rodham Clinton, Jesse Jackson, and John Kerry.

13. In the group sessions, the designated monitor was given five numbered envelopes, to be opened in order as soon as the previous envelope's task was completed. The first three each contained instructions for the group to discuss and reach a consensus, if possible, on one of the three focal issues. A fourth contained individual forms, identical to those they complcted before the groups were convened, which asked for thcir private individual opinions on all three topics after the group discussions were completed. The other envelope asked the group to discuss an unrelated issue. 
Envelope 1, read the question and instructions inside to the group, and then set the timer for 15 minutes. At the end of the 15 minutes, the monitor will record the 'Group Consensus Opinion' (if there is consensus), and then open Envelope 2.

Each discussion should last approximately 15 minutes. DO NOT take straw votes until you are close to the end of your time-use the full 15 minutes.

IMPORTANT NOTE: Be sure not to close discussion before everyone has had a chance to talk.

If you understand these instructions, you can open Envelope 1 and begin discussion on the first topic.

Participants discussed each of the three issues as a group while being videotaped and tried to reach a consensus-defined as a unanimous opinionin fifteen minutes of discussion. After the discussion, they filled out another questionnaire in which they re-rated each issue privately as individuals.

\section{B. Materials Given to Study Participants}

Each group discussed the same three issues, and all members privately rated their personal opinions before and after discussion on a one (Disagree Very Strongly) to ten (Agree Very Strongly) scale.

\section{Table 1. Rating Scale}

$\begin{array}{cccccccccc}\begin{array}{c}\text { Disagree } \\ \text { Very }\end{array} & \begin{array}{c}\text { Disagree } \\ \text { Strongly }\end{array} & \text { Disagree } & \begin{array}{c}\text { Disagree } \\ \text { Somewhat }\end{array} & \begin{array}{c}\text { Disagree } \\ \text { Slightly }\end{array} & \begin{array}{c}\text { Agree } \\ \text { Slightly }\end{array} & \begin{array}{c}\text { Agree } \\ \text { Somewhat }\end{array} & \text { Agree } & \begin{array}{c}\text { Agree } \\ \text { Strongly }\end{array} & \begin{array}{c}\text { Agree } \\ \text { Very } \\ \text { Strongly }\end{array} \\ 1 & 2 & 3 & 4 & 5 & 6 & 7 & 8 & 9 & 10\end{array}$

The text of the three issues given to study participants said:

1. The United States should sign an international agreement to reduce the greenhouse gases produced in this country that contribute to global warming.

2. When different applicants for the same job or educational opportunity are almost equal on relevant criteria, then the job or admission should be given to members of groups in society that have been discriminated against in the past.

3. Two adults of the same sex should be able to form a "civil union," which would entitle them to certain legal rights such as joint home ownership, or access to the other's retirement or medical benefits.

We chose these issues because they divide people sharply along political lines and have done so for a significant period of time. Undoubtedly, other political issues would have worked as well. The first questionnaire also included 
demographic information and some filler items. ${ }^{14}$

\section{Study Results}

The recruitment process was successful in assembling groups in Boulder that were, on average, significantly more liberal than those in Colorado Springs in their initial opinions. ${ }^{15}$ When combined across all three issues, individual pre-deliberation opinions show substantial differences between the two counties, ${ }^{16}$

Table 2. Summary of Individual Responses

Boulder (liberal)

\begin{tabular}{rcccccc} 
Mean pre- & $\begin{array}{c}\text { Mean post- } \\
\text { deliberation } \\
\text { deliberation }\end{array}$ & $\begin{array}{c}\text { Moved } \\
\text { down }\end{array}$ & $\begin{array}{c}\text { Stayed } \\
\text { same }\end{array}$ & $\begin{array}{c}\text { Moved } \\
\text { up }\end{array}$ & $\begin{array}{c}\% \\
\text { groups } \\
\text { polarized }\end{array}$ \\
\hline $\begin{array}{r}\text { Global } \\
\text { Warming }\end{array}$ & 9.19 & 9.44 & 5 & 18 & 8 & $60 \%$ \\
Affirmative \\
$\begin{array}{r}\text { Action } \\
\text { Civil } \\
\text { Unions }\end{array}$ & 5.81 & 6.38 & 6 & 11 & 15 & $80 \%$ \\
\hline Overall & 8.22 & 9.69 & 1 & 19 & 12 & $100 \%$ \\
\hline & 8.07 & 8.50 & 12 & 48 & 35 & $80 \%$
\end{tabular}

Colorado Springs (conservative)

\begin{tabular}{rcccccc} 
Mean pre- & $\begin{array}{c}\text { Mean post- } \\
\text { deliberation }\end{array}$ & $\begin{array}{c}\text { Moved } \\
\text { dewneration }\end{array}$ & $\begin{array}{c}\text { Stayed } \\
\text { same }\end{array}$ & $\begin{array}{c}\text { Moved } \\
\text { up }\end{array}$ & $\begin{array}{c}\% \\
\text { groups } \\
\text { polarized }\end{array}$ \\
\hline $\begin{array}{r}\text { Global } \\
\text { Warming }\end{array}$ & 5.13 & 2.97 & 2 & 7 & 3 & $100 \%$ \\
$\begin{array}{r}\text { Affirmative } \\
\text { Action } \\
\text { Civil } \\
\text { Unions }\end{array}$ & 2.84 & 1.61 & 1 & 10 & 2 & $100 \%$ \\
\hline Ovcrall & 3.48 & 2.19 & 8 & 18 & 5 & $80 \%$ \\
\hline
\end{tabular}

We now explore the effects of deliberation, separately analyzing the consequences for individual views and the consequences for group decisions.

14. The filler items appeared in-between the three group discussion issues, and were: "Having family members nearby is an important part of a good quality of lifc," "lt is better to live in the country than in the city or a suburb," and "The health care that 1 receive is worse than it was in the past."

15. See infra Table 1 .

16. A repeated measures ANOVA (Analysis of Variance) showed that there were highly significant differences between the two samples im their pre-deliberation opinions on the issues to be discussed: $F(1,61)=234.3$, $(p<.001)$. This difference was separately significant for each of the three issues (each issue $p<.001$ ). 


\section{Individual Mean Shifts Toward Extremity}

The opinions of individuals showed consistent evidence of ideological amplification. Six groups produced individual means that shifted in the same direction as the general leaning of the group for all three issues, and the other four groups did so on two of the three issues. There were a total of thirty group discussions, or ten groups discussing three issues per group. Overall, then, twenty-six of thirty discussions, or $87 \%$, produced ideological amplification in individual judgments. An analysis of the medians produced essentially identical results.

This pattern of amplification is confirmed in a more formal analysis. For all individuals, we subtracted pre-deliberation opinions from post-deliberation opinions on each issue, so as to produce an opinion shift "difference score." For the liberal groups, a positive difference would represent amplification, while a negative difference would represent the same thing for the conservative groups. This is in fact exactly what we observe, as Table 1 demonstrates. This difference between geographical locations is highly significant, $F(1,61)=56.1$, $\mathrm{p}<.001$, and is separately significant for each issue (global warming $\mathrm{p}<.001$, affirmative action $p<.001$ and civil unions $p<.02$ ). Thus we clearly observe a shift toward more extreme opinions in both liberal and conservative groups, but in opposite directions.

There is a small-but statistically significant-tendency for the conservative groups to shift their opinions more, after discussion, than do the liberal groups $(p<.01)$. But it would be a mistake to pay much attention to this difference. While some groups would undoubtedly shift more than others, the difference found here is probably an artifact of the fact that on global warming and civil unions, liberal groups were more extreme at the beginning, so that there was less room for them to move after discussion. ${ }^{17}$

\section{Differentiation: The Gap Between Liberals and Conservatives}

Liberals and conservatives have different opinions and beliefs about many social and political issues, and it is no surprise that they might come to our study with differences on the particularly salient and controversial issues that we chose for discussion. ${ }^{18}$ Despite this general pattern of differences, before deliberation there was actually a substantial amount of overlap between opinions in Boulder and Colorado Springs. ${ }^{19}$

What is the effect of deliberation, by like-minded groups, on the differences? The answer is simple: because of the ideological amplification resulting from the group process, the initial gulf between opinions in the two counties ( 8.07 for Boulder vs. 3.48 for Colorado Springs, a difference of 4.59)

17. See supra Table 1.

18. See supra Table 1. See also supra note 12.

19. See infra Figure 1, top panel. 
grew far wider ( 8.50 for Boulder vs. 2.26 for Colorado Springs, a now much larger difference of $6.24, p<.001$ ). Perhaps more disturbing, the distribution of opinions is now heavily concentrated in the extremes, and most of the overlap in opinions between the two locations has disappeared. ${ }^{20} \mathrm{~A}$ main effect of deliberation among like-minded people, then, was a growing gap between liberals and conservatives.

Figure 1. Pre- and Post-Deliberation Distributions of Opinions

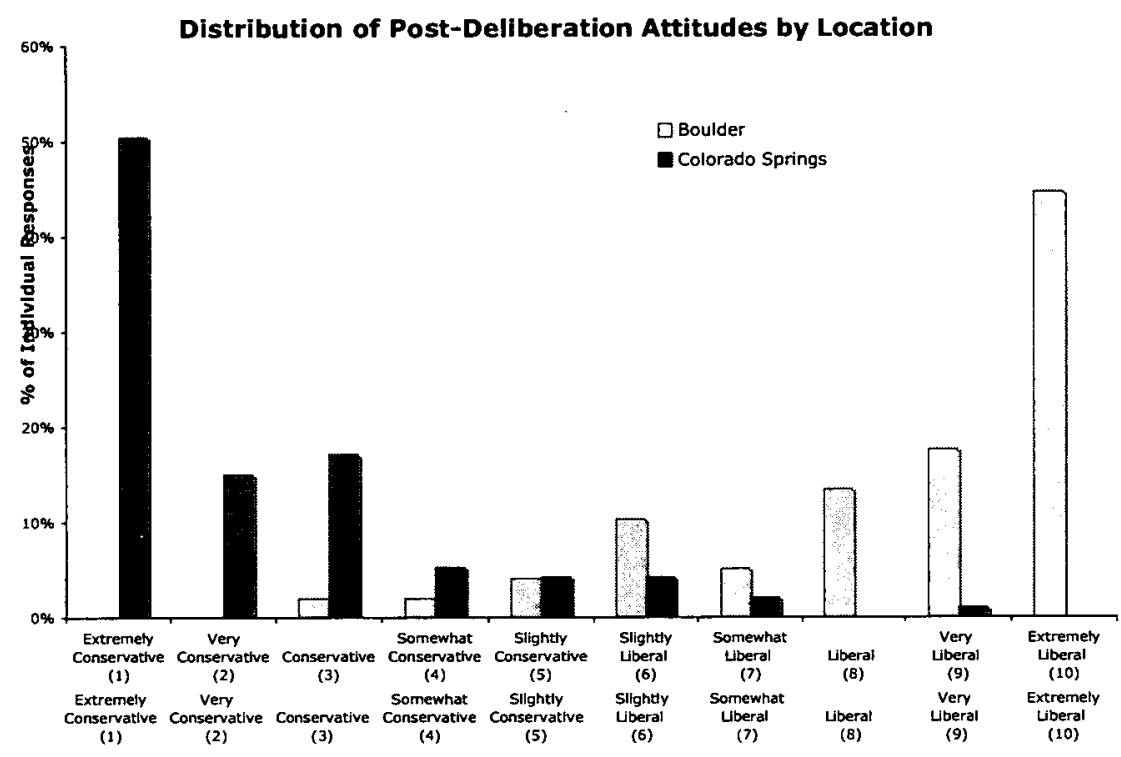

\section{Reduced Internal Diversity}

Another important question about deliberation is whether participants will converge or diverge during and as a result of the process of deliberation. A common method for measuring diversity in opinions is by their standard deviation. The result is clear: the diversity of opinion within our groups, as measured by the standard deviation of their ratings on an issue, was markedly lower after deliberation. ${ }^{21}$ The standard deviation of individual opinions in the group was lower after deliberation for no fewer than twenty-nine of the thirty group-issue combinations, and fell from a median of 1.17 pre-deliberation to 0.69 post-deliberation $(\mathrm{z}=4.7, \mathrm{p}<.001$, by a sign test). In other words, delibcration greatly decreased the heterogeneity of opinions within a group.

A similar pattern can be found if we look across groups within the same county. The standard deviation among groups in Boulder declined from 0.67 to 0.51 , and in Colorado Springs from 0.85 to 0.76 . After deliberation, the

20. See infra Figure 1, bottom panel.

21. See infra Figure 2. 
opinions of even different groups of people from the same place were more similar-despite not talking with each other. Overall, then, deliberation created far more homogeneity of opinion within different groups from the same geographical location.

Figure 2. Opinion Diversity Declines After Deliberation

Comparison of Pre and Post Standard Deviations of Individuai Opinions Within a Group

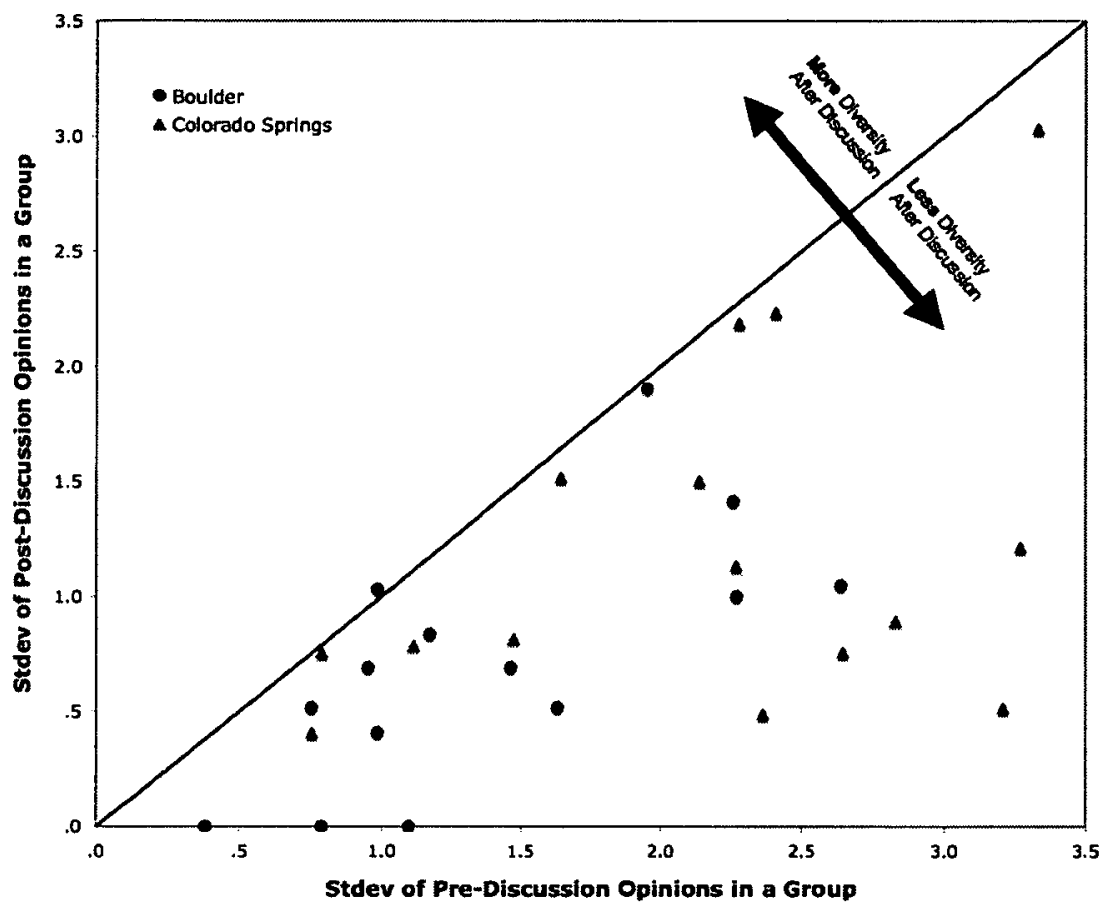

\section{Group Decisions}

What is the relationship between pre-deliberation individual views and the views of deliberating groups? This question is of independent interest. Much of the time, what matters is what groups think and do as such, not only what their members think and do as individuals. The basic answer is that group decisions were more extreme than the mean or median of pre-deliberation judgments.

Overall, twenty-five of thirty groups, or $83 \%$, reached a unanimous decision on a numerical scale response within fifteen minutes - ten of ten on global warming, seven of ten on affirmative action, and eight of ten on civil unions. Among the twenty-five group-issue combinations on which a consensus was reached, nineteen groups, or $76 \%$, reached a consensus decision that was more extreme than the mean pre-deliberation individual opinion of group members. The same figure holds for median pre-deliberation responses. 
II

\section{EXPLANATIONS AND IMPLICATIONS}

On our Deliberation Day, individual liberals grew more liberal and individual conservatives grew more conservative. Within groups, internal diversity diminished, and the gap between liberals and conservatives grew. Why did this happen?

\section{A. Conformity, Ideological Amplification, and Group Polarization}

\section{Consensus and Polarization in General}

When people discuss their beliefs and preferences in groups, consensus increases for two reasons. The first involves basic conformity or herding habits, which lead people to defer to the opinions of others-whether or not an individual actually agrees with those opinions. ${ }^{22}$ The second is that people learn from the information and views of others. As a result, discussion can produce significant changes in points of view. ${ }^{23}$

Mere deference, in public, to the views of others would not always be expected to affect anonymous statements of opinion. People's public statements on an issue may well diverge from their private views. ${ }^{24}$ Indeed, we observed greater diversity in people's anonymous statements than in the views of groups. But when a group member has signed onto an official view, the private statement might be affected as well-if only because it is disconcerting to maintain a view in private that diverges from a statement made in public. ${ }^{25}$ In any event, group members who learn from one another are likely to be affected in their anonymous statements as well as their public ones, and hence we observe a significant increase in internal group consensus, even with respect to privately held views, as a result of deliberation. That phenomenon has not been studied extensively in empirical terms, but it seems familiar in many types of groups, including political parties, religious organizations, university faculties, labor unions, student groups, and corporate boards.

22. See Solomon Asch, Opinions and Social Pressure, in Readings About the Social Animal 13 (Elliott Aronson ed., 7th ed. 1995); Leon Festinger, A Theory of Social Comparison Processes, 7 Hum. Rel. 117 (1954); Muzafer Sherif, An Experimental Approach to the Study of Attitudes, 1 SOciometry 90 (1937). A good discussion of the effects of conformity can be found im Lee Ross \& Richard E. Nisbett, The Person and the Situation 28-30 (1991).

23. See Daniel Gigone \& Reid Hastie, Proper Analysis of the Accuracy of Group Judgment, 121 Psychol. BulL. 149, 161-62 (1997); Reid Hastie, Review Essay: Experimental Evidence of Group Accuracy, in INFORMATION PoOLING AND Group DECISION MAKING 129, 133-46 (Bernard Grofman \& Guillermo Owen eds., 1986).

24. See Timur Kuran, Private Truths, Public lies (1995) (discussimg general phenomenon of "preference falsification," in which people's public statements are systematically inconsistent with their actual private views).

25. See id. See also Leon Festinger, A Theory of Cognitive Dissonance (1957) (giving more information on the complex relations between public statements and private views). 
More strikingly, a well-known effect of discussion is group polarization, by which deliberating groups end up in a more extreme position in line with their pre-deliberation tendencies. ${ }^{26}$ In our experiment, group polarization occurred in the particular form of ideological amplification. We find unmistakable evidence of group polarization on the current political and legal issues discussed in this study.

Our findings are noteworthy because most studies of group polarization do not involve legal or political issues. ${ }^{27}$ The original polarization experiments involved risk-taking behavior, with a demonstration that risk-inclined people, when considering (for example) the decision whether to take a new job in a new city or to become a concert pianist, became still more risk-inclined as a result of dcliberation. ${ }^{28}$ With respect to business-related decisions, groups seemed to be willing to take risks that their individual members would avoid. ${ }^{29}$ Later studies of group polarization showed that under some conditions, the "risky shift" could also be a "cautious shift," as risk-averse people become more averse to certain risks after speaking with one another. ${ }^{30}$ It turned out that the direction of the shift - toward greater risk-taking or greater caution-was related to the domain of experience in which the risky choice was embedded. The principal examples of "cautious shifts" involved the decision whether to marry and the decision whether to board a plane despite severe abdominal pain, possibly requiring medical attention. ${ }^{31}$ In these cases, deliberating groups together moved toward a more cautious approach, as did the individual members who composed each of the groups. ${ }^{32}$

26. See Roger Brown, Social Psychology (2d ed. 1986). Two of the present authors have discussed this phenomenon in other places. See, e.g., Cass R. Sunstein, The Law of Group Polarization, 10 J. Pol. PHIL. 175 (2002) [hereinafter Sunstein, Law of Group]; David Schkade et al., Deliberating About Dollars: The Severity Shift, 100 Colum L. Rev. 1139 (2000); Cass R. Sunstein, Deliberative Trouble? Why Groups Go To Extremes, 110 YALE L.J. 71 (2000) [hereinafter Sunstein, Deliberative Trouble].

27. See BRown, supra note 26 , at 200-245 (studying group polarization).

28. See J.A.F. Stoner, A Comparison of Individual and Group Decision Involving Risk (1961) (unpublished Master's thesis, Massachusetts Institute of Technology) (on file with Massachusetts Institute of Technology). An interesting replication of Stoner's findings can be found in Lawrence K. Hong, Risky Shift and Cautious Shift: Some Direct Evidence on the CultureValue Theory, 41 Social Psychol. 342 (1978). Hong finds that Americans are more risk-inclined in groups than as individuals with respect to the decision whether to take a new job, have a heart operation, buy stocks, choose a risky play in football, invest in a foreign country, ehoose a risky move in chess, become a concert pianist, and run for political office. Interestingly, Chinese subjects showed a cautious shift for all these questions, with a single exception: choosing a risky play in football.

29. Stoner, supra note 28; Hong, supra note 28 (finding a risky shift for American subjects).

30. See Serge Moscovici \& Marisa Zavalloni, The Group as a Polarizer of Attitudes, $12 \mathrm{~J}$. Personality \& Soc. Psychol. 125, 125-35 (1969). See also Hong, supra note 28.

31. See Moscovici \& Zavalloni, supra note 30. See also Hong, supra note 28, at 344 (finding a cautious shift for both Chinese and American subjects with respect to the decision whether to marry).

32. See Moscovici \& Zavalloni, supra note 30. 
More careful analysis of these results demonstrated that the predeliberation median is the best predictor of the direction of the postdeliberation shift. ${ }^{33}$ Where group members were predisposed toward risktaking behavior, a risky shift was observed. Where members were more disposed toward caution from the beginning, a cautious shift was observed. Hence, group polarization refers to the tendency of deliberating groups to shift to a more extreme position in line with the pre-deliberation tendencies of their members. Ideological amplification, as we use the term here, is best understood as a special case of group polarization.

In the behavioral laboratory, group polarization is evident in a remarkably wide range of contexts, including robbery, aesthetic judgments and factual observations. ${ }^{34}$ For instance, even groups of burglars can show a shift in the cautious direction when they discuss prospective criminal endeavors. ${ }^{35}$ Group deliberation produces more extreme judgments about the attractiveness of people shown in slides. ${ }^{36}$ Deliberation can also produce more extreme group judgments for obscure factual questions, such as how far Sodom (on the Dead Sea) is below sea level. ${ }^{37}$

Our focus here has been on disputed political questions. In the domain of law, there is some evidence of group polarization as well. In punitive damage cases, deliberating juries have been found to polarize, producing awards that are often higher than those of the median juror before deliberation begins. ${ }^{38}$ When individual jurors begin with a high level of moral indignation about a defendant's conduct, juries become more indignant after deliberation than their median member had been before discussion. This effect ultimately produces dollar awards that are often as high as or even higher than the highest award favored before deliberation by any individual juror. ${ }^{39}$ Group polarization also occurs for jury judgments of guilt and sentencing in criminal cases. ${ }^{40}$ With respect to legal questions, pancls of appellate judges polarize too. In ideologically contested areas, Republican appointees show especially conservative voting patterns when sitting on panels consisting entirely of Republican appointees, and Democratic appointees show especially liberal

33. See id. See also Brown, supra note 26, at 210-12.

34. John C. Turner et al., Rediscovering the Social Group: A SelfCategorization Theory 142-70 (1987).

35. Paul F. Cromwell et al., Group Effects on Decision-Making by Burglars, 69 PsYCHOL. REP. 579, 586 (1991).

36. TURNER ET AL., supra note 34 , at 153.

37. Id.

38. See Schkade et al., supra note 26.

39. See id. (finding that in $27 \%$ of the cases, the jury's award was as high or higher than those favored by any individual juror before deliberation).

40. David G. Myers \& Martin F. Kaplan, Group-Induced Polarization in Simulated Juries, 2 Personality \& Soc. PSychol. Bull. 63 (1976); Martin F. Kaplan, Discussion Polarization Effects in a Modified Jury Decision Paradigm: Informational Influences, 40 SOCIOMETRY 262 (1977). 
voting patterns when sitting solely with other Democratic appointees. ${ }^{41}$

There is also suggestive evidence of group polarization on political issues. As a result of deliberation, French people, on average, become more distrustful of the United States and its intentions with respect to foreign aid. ${ }^{42}$ Similarly, feminist ideals can become more attractive to women after internal group discussions. ${ }^{43}$ White people who are not inclined to show racial prejudice show less prejudice after deliberation with one another than before; but white people who are inclined to show such prejudice show more prejudice after deliberation with group members holding similar views. ${ }^{44}$

\section{Sorting versus Mixing}

In our experiment, people were sorted into like-minded groups. Geographical factors - the different voting patterns in Boulder and Colorado Springs-greatly simplified this sorting process. Such sorting was a central part of the design of our study, because we were explicitly interested in the effects of deliberation among and across like-minded groups. As we suggested, actual sorting appears to be increasing in geographical terms, as geographically defined areas within the United States are becoming more uniform in their political commitments. ${ }^{45}$ In addition, virtual sorting across political lines is far easier with the rise of media organized along ideological lines. ${ }^{46}$

It is natural to ask what would have happened if there had been a degree of mixing -if people from Colorado Springs had participated in groups with people from BouIder. Advocates of deliberation typically prefer heterogeneity rather than uniformity. ${ }^{47}$ Mixing might have occurred voluntarily, as it often does. Alternatively, mixing might have been engineered by the experimental design. In terms of ultimate outcomes, existing work suggests two principal possibilities. First, and most likely, the pre-deliberation median might well have been predictive here as well, in the sense that it would likcly predict both the group's decision and the shift in individual views. ${ }^{48}$ Suppose, for example, that a group of six people tended to oppose civil unions for same-sex couples,

41. See Cass R. Sunstein, David A. Schiade, LiSa M. Ellman \& Andres Sawicki, Are Judges Political? An Empirical Analysis of the federal Judiciary (2006) [hereinafter Sunstein et al., Are Judges Pol1t1Call; Cass R. Sunstein et al., Ideological Voting on Federal Courts of Appeals: A Preliminary Investigation, 90 VA. L. REv. 301 (2004) [hereinafter Sunstein et al., Ideological Voting].

42. BROWN, supra note 26 , at 224 .

43. David G. Myers, Discussion-Induced Attitude Polarization, 28 HUM. REL. 699, 707 11 (1975) (finding increase in support for feminism among women inclined to show feminist attitudes).

44. David G. Myers \& George D. Bishop, Discussion Effects on Racial Attitudes, 169 SCIENCE 778, 778-79 (1970).

45. See Bishop, supra note 5 .

46. See id.

47. See ACKERMAN \& FiShKIN, supra note 3.

48. See Brown, supra note 26, at 210-12. 
because two members sharply opposed them, two members mildly opposed them, and two members mildly favored them. In light of the initial distribution of views, the group and its individual members wouId probably move in the direction of greater opposition, notwithstanding a degree of internal heterogeneity. In many settings, the pre-deliberation median is the best predictor of the movement of individual and groups, even if there is a degree of antecedent heterogeneity. ${ }^{49}$ Note, in this regard, that aII of the groups in our study began with some such heterogeneity, and they nonetheless moved in the way predicted by group polarization research. As discussed below, this conclusion follows from an understanding of the sources of polarization.

The second possibility is that individual positions will be further entrenched in their preexisting views and will fail to move at all, as group members may show a reluctance to listen to those with competing positions. Polarization may not be found when the relevant group consists of individuals drawn equally from two extremes. ${ }^{50}$ Consider the finding that "familiar and long-debated issues do not depolarize easily." "We have said that ideological amplification generally occurs in the federal judiciary. ${ }^{52}$ But on two issuescapital punishment and abortion-Republican appointees are not affected by sitting with two Democratic appointees, and Democratic appointees are impervious to the influences of two Republican appointees. ${ }^{53}$ Evidently judicial judgments about abortion and capital punishment are firmly held and hence amplification does not occur. For political issues on which people do not have rigidly determined positions, polarization is more likely, as our own experiment suggests.

Mixed groups have, however, been shown to have two desirable social effects. First, exposure to competing positions generally increases political tolerance. ${ }^{54}$ After hearing a variety of views, including those divergent from their own, many people become more respectful of alternative positions and are more willing to consider them plausible or legitimate. An important result of seeing a political conflict as legitimate is a "greater willingness to extend civil liberties to even those groups whose political views one dislikes a great deal." 55 Second, mixing increases the likelihood that people will be aware of competing rationales and will see potential counterarguments. ${ }^{56}$ This effect is especially pronounced for those who antecedently show a "civil orientation toward

49. See Schkade et al., supra note 26 , at $1140-41$ (finding that the pre-deliberation median predicts movements, even when there is considerable internal diversity).

50. See E. Burnstein, Persuasion As Argument Processing, in Group Decision Making (Hermann Brandstetter et al. eds., 1982).

51. BRown, supra note 26, at 226.

52. Sunstein ET AL., ARE JUdges Political, supra note 41, at 22-24.

53. See id. at 62-63 (discussing decisions of three-judge panels).

54. See MuTz, supra note 4, at 76-77.

55. Id. at 85 .

56. Id. at 74-76. 
conflict," in the sense that they are committed to a degree of social harmony and are willing to acknowledge, in advance, that dissenting views should be expressed. ${ }^{57}$ These desirable effects of deliberation within mixed groups will not be realized in any deliberative process in which people are sorted, or sort themselves, into politically homogeneous groups.

\section{B. Explaining Polarization}

Why does group polarization occur, and what accounts for such ideological amplification? Contributing factors include (a) informational influences, (b) corroboration effects, (c) social comparison, and (d) shared identity and self-categorization. ${ }^{58}$

\section{Informational Influences}

The first and perhaps most important reason is that group members provide relevant information. ${ }^{59}$ In Colorado, group members were willing to consider both the conclusions and the arguments offered during deliberation. For example, skeptics made slippery slope arguments about same-sex marriage, expressing the fear that further changes to the institution of marriage will be difficult to prevent if that institution is not limited to one man and one woman. With respect to affirmative action, those rejecting color blindness emphasized the long history of discrimination in the United States and argued that a principle of color blindness might return the nation to a time of greater racial inequality. Group members were responsive to both of these concerns.

In any group with some initial inclination, the views of most people in the group, and the information that they have and that they provide, will inevitably tend in the direction of that inclination. ${ }^{60}$ Suppose, for example, that most people in a group believe that an international treaty to control global warming is a bad idea. As a statistical matter, the arguments favoring that initial position will be more numerous than the arguments pointing in the other direction. Individuals may have been exposed to some, but not all, of the arguments that emerge from group deliberation; perhaps they will not have heard concerns about the expense of international controls, the dangers of ceding national controls over energy policy, or the possibility that global warming will have only modest adverse effects for the United States. As a result of hearing the various arguments, deliberation will lead people toward a more extreme point aligned with the initial beliefs of group members. Through this process, many

57. Id. at 75 .

58. See Brown, supra note 26, at 212-22, 226-45; Robert S. Baron et al., Social Corroboration and Opinion Extremity, 32 J. ExPERIMENTAL Soc. Psychol. 537 (1996). Overlapping accounts are provided in Schkade et al., supra note 26, and Sunstein, Deliberative Trouble, supra note 26.

59. BRown, supra note 26 , at 217-22.

60. Id. at 219. 
minds can polarize, and in exactly the same direction.

\section{The Effects of Corroboration and "Self-Discovery"}

The second explanation stresses the close links among confidence, extremism, and corroboration by others. ${ }^{61}$ If people lack confidence, they will tend toward the middle and avoid the extremes. ${ }^{62}$ As people gain confidence, they usually become more extreme in their beliefs. ${ }^{63}$ Agreement from others tends to increase confidence, and in this way like-minded people become more certain they are right and thus more extreme after deliberating with each other ${ }^{64}$ In a wide variety of experimental contexts, people's opinions have been shown to become more extreme simply because their views have been corroborated, and because they have become more confident after learning that others share their views. ${ }^{65}$

A process of this kind undoubtedly occurred in Colorado. Within both liberal and conservative groups, some people began with a degree of tentativeness, in a way that moved them toward the middle of the relevant scale. ${ }^{66}$ After hearing both conclusions and arguments that fortified their original inclinations, they moved, with remarkable regularity, to a more extreme position. ${ }^{67}$

A distinctive but related account of group polarization, and hence ideological amplification, suggests that deliberation can operate as a form of "self-discovery." 68 This account begins with the observation that particular people are likely to find particular arguments especially persuasive. Fundamentalist Christians might be convinced, for example, that climate change, induced by some human beings to the detriment of other human beings and the natural world, is inconsistent with their deepest theological commitments. For those who think about political issues, some reasons are "active," in the sense that they are known to be valid and relevant, whereas other reasons are "latent," in the sense that people are uncertain of their pertinence and strength, but might be much affected by them if they are pressed in deliberation. ${ }^{69}$ When people find themselves in groups of like-minded people, their latent judgments are made active, as others press reasons in favor

61. See Baron et al., supra note 58, at 557-59 (showing that corroboration increases confidence and hence extremism).

62. See id.

63. Id.

64. Id.

65. See Baron et al., supra note 58 at $541,546-47,557$ (concluding that corroboration of one's views has effects on opinion extremity).

66. See supra Figure 1, top panel.

67. See supra Figure 1, bottom panel.

68. See Catherine Hafer \& Dimitri Landa, Deliberation and Social Polarization, Jan. 25, 2006, available at http://ssm.eom/abstract $=887634$.

69. Id. at 2 . 
of those judgments. It is in this sense that deliberation can operate as a form of "self-discovery," producing ideological amplification. This account is also consistent with what we observed in Colorado.

\section{Social Comparison}

The third explanation involves social comparison. ${ }^{70}$ Sometimes people's publicly stated views are partly a function of how they want to present themselves. ${ }^{71}$ People usually want to be perceived favorably by other group members. ${ }^{72}$ Once they hear what others believe, some will adjust their positions at least slightly in the direction of the dominant position, to present themselves in the way that they prefer.

Reputational concerns are only part of the story here; people also want to preserve their preferred self-conception, and if they ordinarily think of themselves slightly left-of-center, they might shift a bit, in a liberal group, in order to preserve that self-conception. In a liberal group, movements in the liberal direction will be favored and, for this reason, all members might end up leaning somewhat more to the left. This explanation fits well with the changes we observed.

\section{Shared Identity and Self-Categorization}

A great deal of research indicates that group polarization is heightened when people have a sense of shared identity ${ }^{73}$ People may polarize because they are attempting to conform to the position they see as typical or normative within their own group. If a group's particular identity is especially salient, the in-group norms "are likely to become more extreme so as to be more clearly differentiated from outgroup norms, and the within-group polarization will be enhanced." ${ }^{74}$ When Democrats or Republicans polarize, the desire to ensure intergroup differentiation is likely a motive. In our own experiment, many groups were even more prone to polarization when their discussions refcrred to groups with whom they disagreed, such as "those loony liberals" or "those crazy conservatives."

\section{The Limits of Polarization: Diverse Deliberation Days}

We have traced several social-cognitive processes that contribute to ideological amplification within like-minded groups: (1) informational

70. See Brown, supra note 26, at 213-17.

71. Id.

72. Id.

73. See id. at 209-11; TURNER ET AL., supra note 34, at 159-70 (discussing evidence for the "self-categorization theory of polarization"); Joel Cooper et al., Attitudes, Norms, and Social Groups, in Blackwell Handbook of Group Psychology: Group Processes 259, 269-70 (Michael A. Hogg \& R. Scott Tindale eds., 2001).

74. TURNER ET AL., supra note 34, at 210. 
influences, (2) corroboration effects, (3) social comparison, and (4) shared identity and self-categorization. An understanding of these processes suggests that political deliberation is extremely likely to lead to ideological amplification. It also suggests circumstances that may dampen or prevent ideological amplification. Imaginable interventions might produce different kinds of shifts and could either intensify or dampen amplification.

1. Informational interventions. We could easily imagine that information flows could affect amplification. Suppose, for example, that we gave the Boulder participants credible information suggesting global warming is not a particularly serious problem for the United States, that affirmative action greatly hurts those whom it is intended to help, or that civil unions for same-sex couples provide few benefits to such couples while posing legitimate threats to children. Such information could counteract the dynamics of ideological amplification, especially if the participants had some reason to trust the source of that information.

For instance, participants may trust news sources that share their political beliefs. $^{75}$ If we told participants from Colorado Springs that President Bush supported a treaty to control global warming or that Vice President Cheney favored civil unions for same-sex couples, some of them would likely be influenced, especially if arguments supported the relevant views. ${ }^{76}$ On the other hand, a deliberately balanced presentation that offers plausible arguments from both sides should diminish the effects that produce ideological amplification.

2. Administrators, moderators, and leaders. Administrators, moderators, and leaders might affect and perhaps even prevent ideological amplification. If group members trust them, administrators can dampen amplification by countering the group's prevailing tendency and attempting to prevent extreme movements. Alternatively, deliberation could include planted membersconfident, likeable, and apparently expert group members who are actually confederates of the experimenter. These confederates should be able to increase or to decrease amplification. ${ }^{77}$

75. See Geoffrey L. Cohen, Party Over Policy: The Dominating Impact of Group Influence On Political Beliefs, 85 J. Personality \& Soc. Psychol. 808 (2003) (showing that identification of a political party's view greatly affects people's judgments on political issues, enough so as to press them away from the view that they would otherwise hold).

76. See id. (noting that the policy favored by the relevant party affected participants' views, even without supporting arguments); See also World Public Opinion.org, Global Warming, $\mathrm{http} / / /$ americans-world.org/digest/global_issues/global_warming/gw2.cfm (last visited Feb. 2, 2007) (noting that about $70 \%$ of Americans favor the Kyoto Protocol to curtail global warming but that figure drops to about $43 \%$ when people are informed that President Bush rejects the Kyoto Protocol).

77. Sherif, supra note 22. A good outline can be found in Ross \& NISBET, supra note 22, at 28-30. For demonstrations of the powerful effect of a confident confederate on the views of group members, See Robert Jacobs and Donald Campbell, The Perpetuation of An Arbitrary Tradition Through Several Generations of a Laboratory Subculture, 62 J. ABNORMAL AND SOCIAL Psych. 649 (1961); Gregory Moschetti, Individual Maintenance and Perpetuation of $A$ Means/Ends Arbitrary Tradition, 40 SOCIOMETRY 78 (1977). 
The group's assessment of administrators or confederates as relatively similar or relevantly different will affect their influence on the group. ${ }^{78}$ In our experiment, deliberators attempted to reach a group decision, and they succeeded in doing so in $83 \%$ of group discussions. The effects we describe would likely diminish if experimenters asked deliberators to speak to one another without reaching a decision and then polled privately on their views.

3. Other Deliberation Days. With respect to the effects of information flows and administrators, there is no need to speculate here. James Fishkin, an advocate of a Deliberation Day with balanced presentations of views, has illuminatingly explored the idea of a "deliberative opinion poll," in which diverse people are asked to engage in deliberation about various issues. ${ }^{79}$ Fishkin finds significant changes in individual opinions, suggesting that deliberation is having a large effect, but he does not find a systematic tendency toward ideological amplification. ${ }^{80}$ In England, for example, deliberation led to reduced interest in using imprisonment as a tool for combating crime even when there was no antecedent hostility to the use of imprisonment. ${ }^{81}$ In the United States, deliberation increased the percentage of people holding a minority position about some issues. For example, deliberation led to a jump from $36 \%$ to $57 \%$ of people favoring policies making divorce "harder to get." 82 Before deliberation, $36 \%$ of people agreed that the "biggest problem facing the American family" is "economic pressure." After deliberation, that number jumped to $51 \%{ }^{83}$ By contrast, the percentage believing that the biggest problem is the breakdown in family values fell from $58 \%$ to $48 \%{ }^{84}$ These changes are very different from what we observed in Colorado, and they do not show ideological amplification.

The deliberative opinion poll uses several of the interventions described above. A trained moderator oversaw Fishkin's groups to ensure a level of openness and likely altered some of the dynamics that produce amplification. ${ }^{85}$ Fishkin also presented partieipants with a set of written materials that attempted

78. See Wendy Wood et al., Minority Influence: A Meta-Analytic Review of Social Influence Processes, 115 Psychol. Bull. 323 (1994) (exploring when minority has impact and when it does not).

79. See James S. Fishrin, The Voice of the People: Public Opinion and Democracy 161-81 (1995) (hereafter FiSHKIN, VOICE OF THE PEOPLE). For valuable and up-to-date materials, See James Fishkin, Ctr. for deliberative democracy, Deliberative Polling®: Towards a BETTER-1NFORMED DEMOCRACY, http://cdd.stanford.edu/polls/docs/summary (last visited Mar. 5, 2007) (hereafter Fishkin, Deliberative Polling)

80. See Fishkin, Deliberative Polling, supra note 79.

81. Id. at $178-79$.

82. Fishkin, Deliberative Polling, supra note 79; See also Fishkin, Voice of the PEOPLE, supra note 79, at 22 (showing an increase, on a scale of 1 to 3, from 1.40 to 1.59 in commitment to spending on foreign aid; also showing a decrease, on a scale of 1 to 3 , from 2.38 to 2.27 in commitment to spending on social security).

83. Fishkin, Deliberative Polling, supra note 79.

84. Id.

85. Id. 
to be balanced and that contained detailed arguments supporting competing positions. ${ }^{86}$ In our study, people relied only on the beliefs, information, and values they brought with them to the room. Fishkin's balanced presentation would likely influence people in a way that simple group discussion without external materials would not. Whatever the experimenter's goals, the materials that are provided will undoubtedly affect the direction that deliberation will take group members.

Finally, Fishkin instructed his participants not to reach a group decision, and the absence of such a decision probably attenuated the influences discussed here. We have suggested that when individuals commit themselves to a group judgment, it is likely that their individual responses, even if anonymous, will be somewhat affected by that commitment. To disclose a private judgment that diverges from one's public judgment is certainly possible, but it produces a degree of dissonance, which is often resolved in favor of the public statement. ${ }^{87}$ Group polarization has been found after mere exposure to the arguments of other group members, but it is typically smaller than after discussion and group judgment. $^{88}$

It is tempting to explain Fishkin's results by noting that his groups were diverse and did not consist of like-minded people. But the temptation should be resisted. Even if a group has a degree of internal diversity on some question, the pre-deliberation median is a good predictor of the post-deliberation median, at least if individual views are not entrenched. ${ }^{89}$

It would be most informative to test the effects of a variety of interventions into deliberative processes in order to see their various contributions to ideological amplification or dampening. It would also be informative to conduct deliberative opinion polls specifically testing the claim that deliberating groups will reach the correct result on political questions that have answers that can be shown to be right. We do not know whether a hypothesis of that kind might be vindicated. Undoubtedly, there is a relationship between the nature of the interventions and the likelihood that the group will arrive at the truth.

There is no question that other Deliberation Days, offering distinctive safeguards and procedures, would have different consequences from those we found in Colorado. Our only suggestion here is that on political issues, the likely result for deliberating groups, unaccompanied by an external moderator or a set of independent arguments, is amplification of preexisting views,

86. $I d$.

87. See Robert B. Cialdini, Influence: The Psychology of Persuasion ch. 3 (I993).

88. See Brown, supra note 26 , at 220 (noting mere exposure produces significant shifts).

89. See id. at 210-II; Schkade et aI., supra note 26, at $1140-41$ (finding that predeliberation median is predictor of shift, whether or not therc is internal diversity before discussion began). 
especially if group members are asked to reach a collective decision.

\section{Implications}

Does ideological amplification lead to accuratc or inaccurate answers? Do deliberating groups err when they polarize? No general answer would make sense. A great deal will turn on the relationship between the correct answer and the group's pre-deliberation tendencies. If the group is leaning toward the right answer, polarization might lead them directly to the truth. But there are no guarantees here. When individuals are leaning in a direction that is mistaken, the mistake will be amplified by group deliberation.

Consider some results from domains in which mistakes and biases can be identified without taking a controversial stand on normative issues. With respect to questions with correct answers, deliberating groups tend to do about as well as or slightly better than their average member, but not as well as their best members. ${ }^{90}$ Further, deliberating groups do not reliably arrive at the correct answer. ${ }^{91}$ Group polarization occurs when jury members are biased as a result of pretrial publicity; the jury as a group becomes more biased than the individual jurors. ${ }^{92}$ When most people are prone to make conjunction errors (believing that $\mathrm{A}$ and $\mathrm{B}$ are more likely together than $\mathrm{A}$ or $\mathrm{B}$ alone), group processes lead to more errors, not fewer. ${ }^{93}$ The propensity to make conjunction errors is amplified, rather than reduced, by deliberation, apparently as a direct result of the mechanisms discussed here. Hence it is possible to show that in many domains, deliberation results in an amplification of individual mistakes. ${ }^{94}$

When individuals show a high degree of bias, groups are likely to be more biased than their median or average membcrs. ${ }^{95}$ It is true that deliberating groups do well on "eureka" problems-those for which the answer is obvious once announced. $^{96}$ It has been found, for example, that when sending and receiving information is costless, groups do significantly better on math problems than do individuals, apparently because people are able to recognize a

90. See Gigone \& Hastie, supra note 23.

91. See id. at 161-62 (summarizing findings that groups do not perform as well as best meinbers); Hastie, supra note 23, at 133-49. To the same effect, see also Garold Stasser \& Beth Dietz-Uhler, Collective Choice, Judgment, and Problem Solving, in Blackwell HandBook of Group Psychology: Group Processes, supra note 73, at 31, 49-50 (collecting findings).

92. Robert J. MacCoun, Comparing Micro and Macro Rationality, in JUDGMENTS, Decisions, and Public Policy 116, 127-28 (Rajeev Gowda \& Jeffrey C. Fox eds., 2002).

93. Norbert L. Kerr et al., Bias in Judgment: Comparing Individuals and Groups, 103 PSYCHOL. REV. 687, 692 (1996).

94. William P. Bottoin et al., Propagation of Individual Bias Through Group Judgment: Error in the Treatment of Asymmetrically Informative Signals, 25 J. RisK \& UNCERTAINTY 147, 152-54 (2002).

95. See MacCoun, supra note 92.

96. See Cass R. Sunstein, Infotopia: How Many Minds Produce Knowledge 60-61 (2006). 
correct answer as such. ${ }^{97}$ But many problems do not have this feature because the correct answer is not immediately recognizable, and hence group error is pervasive.

More generally, a comprehensive study demonstrated that majority pressures can be powerful even for factual questions on which some people know the right answer. ${ }^{98}$ The study involved 1200 people, forming groups of six, five, and four members. Individuals were asked true-false questions involving art, poetry, public opinion, geography, economics, and politics. They were then asked to assemble into groups to discuss the questions and produce answers by consensus. The clearest result was that the views of the majority played a large role in determining the group's answers. When a majority of individuals in the group gave the right answer, the group's decision followed the majority in no less than $79 \%$ of the cases. The truth played a role too, but a lesser one. If a majority of individuals in the group gave the wrong answer, the group decision nonetheless moved toward the majority position in $56 \%$ of the cases. Hence, the truth did have an influence- $79 \%$ is higher than $56 \%$-and this is a definite point in favor of the potentially beneficial effects of deliberation. But the judgment of the majority, and not the truth, was the dominant influence. And because the majority was influential even when wrong, the average group decision was right only slightly more often than the average individual decision ( $66 \%$ versus $62 \%$ ).

There is a final question. Is our experiment representative of the effects of political deliberation in most domains? We specifically attempted to ensure that our deliberating groups would consist of like-minded people. And it is reasonable to think that much of the time, real-world deliberation looks a lot like our experiment. To be sure, deliberation sometimes occurs within mixed groups, showing far more diversity than those assembled in Boulder and Colorado Springs. As we have seen, mixed groups are also likely to amplify preexisting tendencies, but that pattern is not inevitable, ${ }^{99}$ and such groups have significant advantages, mostly because of the potential effect of minority positions. $^{100}$

Yet it is plausible to suggest that some countries, including the United States, operate to a greater or lesser extent as a collection of special interest enclaves, in which people are especially likely to associate and deliberate with

97. See Mathew D. McCubbins and Daniel B. Rodriguez, When Does Deliberating Improve Decisionmaking?, 15 J. ConTEMP. LeGAL Issues 9, 27-29 (2006), available at $\mathrm{http}: / / \mathrm{ssrn} . \mathrm{com} /$ abstract=900258. Note that when receiving information is costly, individuals did not do better with delibcration than on their own. See id. at 28-32.

98. Robert L. Thomdike, The Effect of Discussion Upon the Correctness of Group Decisions, When the Factor of Majority Influence Is Allowed For, 9 J. Soc. PsYCHOL. 343, 34861 (1938) (exploring effccts of both correctncss and majority pressure on group judgments).

99. See supra text accompanying note 50.

100. See the discussion of minority influences in Cass R. Sunstein, Why Societies NeEd DISSENT 30-32 (2003). 
others who agree with them. ${ }^{101}$ To the extent that migration patterns are now producing more homogeneous subcultures, routine exposure to diverse opinions may become less likely for many people. ${ }^{102}$ Similar results might be produced and reinforced by the rise of highly specialized information sources, above all the internet, which makes it increasingly easy for people to avoid opinions that differ from theirs. ${ }^{103}$ Indeed, there is a well-documented tendency for people to seek information that confirms their existing beliefs and to avoid or devalue disconfirming information ("confirmation bias"). ${ }^{104}$ The ease of finding confirmatory evidence is likely to increase the balkanization of opinion.

Consider in this regard an illuminating little experiment. ${ }^{105}$ Members of a nationally representative group of Americans were asked whether they would like to read news stories from one of four sources: Fox (known to be conservative), National Public Radio (known to be liberal), CNN (often thought to be liberal), and the British Broadcasting Network (whose politics are not widely known to Americans). The stories came in different news categories: American politics, the war in Iraq, racial issues in America, crime, travel, and sports. It turns out that for the first four categories, Republicans chose Fox by an overwhelming margin. By contrast, Democrats split their votes between National Public Radio (NPR) and CNN, while showing a general aversion to Fox. For travel and sports, the divide between Republicans and Democrats was much smaller. By contrast, independents showed no preference for any particular source. In a sense, the experiment showed that private choices tend to replicate our Colorado study, with people gravitating toward stories that shared their antecedent views.

There was another finding, an equally striking one: the network label greatly affected people's level of interest in the same news stories. For Republicans, the identical headline became far more interesting, and the story became far more attractive, if it carried the Fox label. In fact the Republican hit rate for the same news stories was three times higher when it was labeled "Fox News." Interestingly, the hit rate also doubled when sports and travel stories were so labeled. Democrats showed a real aversion to stories labeled "Fox News," and the CNN and NPR labels created a modest increase in their interest. The overall conclusion is that Fox attracts substantial Republican support and that Democratic viewers and readers take pains to avoid Foxwhile CNN and NPR have noticeable but weak brand loyalty among

101. See Bishop, supra note 5; See also Alan 1. Abramowitz et al., Incumbency, Redistricting, and the Decline of Competition in U.S. House Elections, 68 J. PoL. 75 (2006).

102. See Bisbop, supra note 5 .

103. See Cass R. Sunstein, Republic.com 2.0 (forthcoming 2007) for discussion. The Internet also makes it very easy to encounter new and different positions. Ideological amplification might well be less likely if people use the Internet to find such positions.

104. See Raymond S. Nickerson, Confirmation Bias: A Ubiquitous Phenomenon in Many Guises, 2 Rev. Gen. Psychol. 175 (1998).

105. See Iyengar \& Morin, supra note 7. 
Democrats. This is only one experiment, to be sure, but there is every reason to suspect that the result would generalize - that people with identifiable leanings are consulting sources, including websites, that match their predilections, and are avoiding sources that do not cater to those predilections.

It is important to note that there is a distinction between deliberating groups that attempt to reach a shared conclusion (as in our study) and deliberating groups that simply talk (as in Fishkin's studies). Amplification might well be heightened for the former groups; and many real-world groups talk without having to reach a shared conclusion. To this extent, such groups may not show the same degree of amplification that we find. Recall, however, that mere exposure to the views of other like-minded people can produce group polarization. ${ }^{106}$ For this reason, we anticipate that movements of the kind found in Colorado, even if somewhat smaller, would also be found without group decisions.

Nothing said here denies that deliberation might be structured so as to diminish the likelihood of ideological amplification; we havc seen that neutral arbiters, providing information and helping to manage discussion, might have a substantial effect. Various efforts to prime participants might also influence the effects of deliberation. If participants are reminded of the 9/11 attacks, or of events that cast a favorable or unfavorable light on certain positions or even officials, they are likely to be affected, perhaps in a way that will diminish the effects found here. ${ }^{107}$ But whatever the intervention and priming effects, the outcome of our experiment offers important cautionary notes about the consequences of deliberation on political judgments. Ideological amplification, and not necessarily reason or truth, may well be the result of political deliberation, at least if group members share antecedent commitments.

There is a final point. If deliberation results in ideological amplification, it does not follow that deliberation has moved group members in the wrong direction. Suppose that after deliberation, group members become especially hostile to affirmative action or especially receptive to same-sex unions. Has deliberation helped or hurt? Any answer would have to turn on some judgment about the merits. With a factual question, we can readily test whether members have been led to error or truth. But with some questions, no such test is easily available. If amplification occurs, perhaps groups are led, much of the time, in the right direction.

Nonetheless, we should be suspicious of situations in which social interactions lead people to believe a more extreme version of what they thought before they began to talk. If group members were exposed to competing arguments, and to a range of perspectives, at least there would be greater reason

106. Brown, supra note 26 , at 220.

107. See Thomas Pyszczynski et al., In the Wake of 9/II: The Psychology of TERROR (2003). 
for confidence that ultimate conclusions were not an artifact of artificially limited "argumcnt pools."

\section{CONCLUSION}

As a result of deliberation with like-minded others, liberals became more liberal and conservatives became more conservative. On some of the largest issues of the time, discussions by like-minded group members fueled greater extremism, and increased divisions between liberals and conservatives. At the same time, both liberal and conservative groups became more homogeneous; deliberation significantly reduced internal diversity.

We have emphasized that our Deliberation Day was not the same as every imaginable deliberation day, and that many advocates of more deliberation argue in favor of distinctive safeguards and procedures that might ensure different results from those that we have described here. But there is every reason to believe that results of that kind occur not simply in cxperimental settings, but in many real-world domains in which citizens and officials engage in political discussions with one another-especially if they sort themselves into actual or virtual groups of like-minded people. Those who seek to foster broader deliberation, or to celebrate deliberative conceptions of democracy, would do well to keep these points in view. 